\title{
Umbilical Cord Entanglement: Diagnostic and Clinical Repercussions
}

\author{
Ana Martínez-Aspas, Francisco Raga, Luiz E Machado, Francisco Bonilla J r, J uan Carlos Castillo \\ Newton G Osborne, Fernando Bonilla-Musoles
}

\section{ABSTRACT}

The use of three-dimensional (3D) ultrasonography since the first trimester of pregnancy allows the diagnosis and follow-up of cord entanglement throughout the entire pregnancy and delivery.

This technology permits a more accurate diagnosis when compared with two-dimensional (2D) ultrasonography or Doppler.

The vast majority of cord entanglements observed at the end of the first-trimester will persist during the entire pregnancy; delivery outcome is usually not affected by this finding except for cases in which multiple cord entanglement is diagnosed.

Keywords: Doppler, 2D, 3D/4D umbilical cord, Entanglement control through all pregnancy.

How to cite this article: Martínez-Aspas A, Raga F, Machado LE, Bonilla F J r, Castillo J C, Osborne NG, Bonilla-Musoles F. Umbilical Cord Entanglement: Diagnostic and Clinical Repercussions. Donald School J Ultrasound Obstet Gynecol 2012;6(3):225-232.

\section{Source of support $\mathrm{Nil}$}

Conflict of interest: None declared

\section{INTRODUCTION}

The umbilical cord can develop a considerable number of abnormalities, accidents and pathological conditions thatmay have very different obstetric and fetal repercussions. ${ }^{1-4}$ The most common event is nuchal cord, but cord entanglement
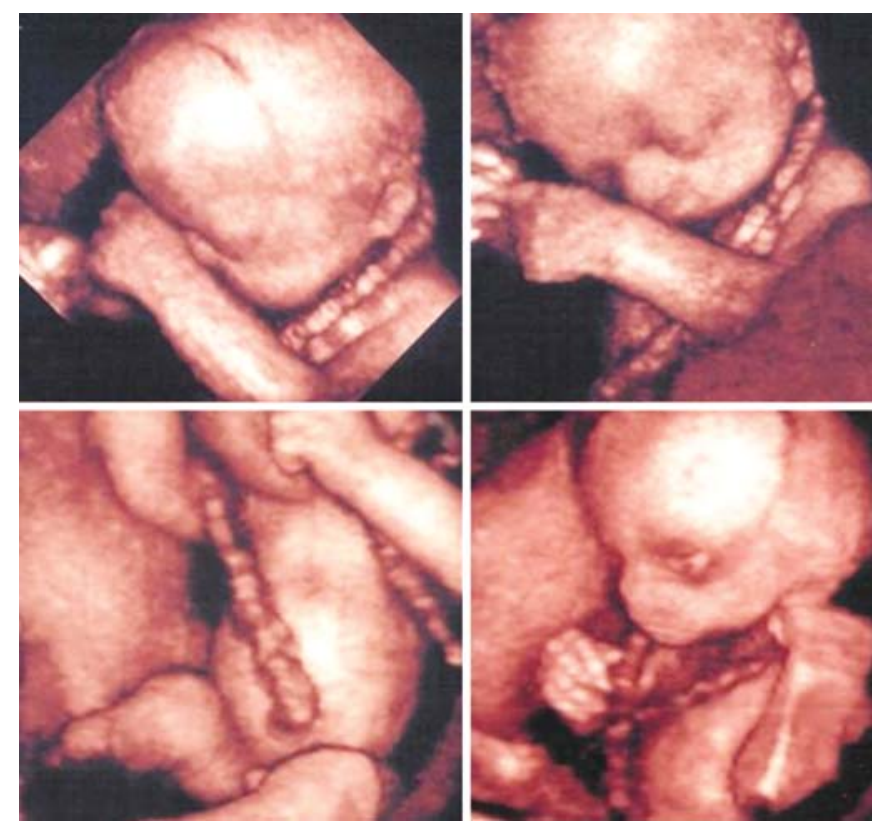

Fig. 1: Four cases of fetuses between weeks 18 and 22 with nuchal cord entanglement around the neck. The below right fetus is a hydrocephalus. The above right fetus shows two loops can take place within the cord itself or around any part of the fetus. This event is seen in 16 to $30 \%$ of all deliveries ${ }^{5,6}$ and a frequency of cord entanglement of up to $38 \%$ has been reported $^{7}$ (Fig. 1).

Up to $2 \%$ of new born babies have a double loop nuchal chord ${ }^{8-15}$ and in $0.5 \%$ of new born babies the cord is w rapped around one of the extremities (Fig. 2).

Cord entanglements can be classified according to the following: 48

- Their nature (tight or loose)

- Number of loops (simple, double, triple or multiple)

- Location (neck, body, extremities or mixed).

A loose nuchal cord is one that can be reduced during delivery by sliding the loop over the head or body of the baby. In contrast, a tight nuchal cord must be clamped and cut to allow delivery of the baby.

Cord entanglement results from active fetal mobility and is facilitated by abundant amniotic fluid (especially if there is polyhydramnios), a long umbilical cord or monoamniotic multifetal pregnancy. A s a consequence there is shortening of the free segment of cord, the extent of which can be estimated by calculating that the segment around the neck in a case of nuchal cord measures about $32 \mathrm{~cm}$, if it is around the leg it measures about 15 and $10 \mathrm{~cm}$, if it is around an
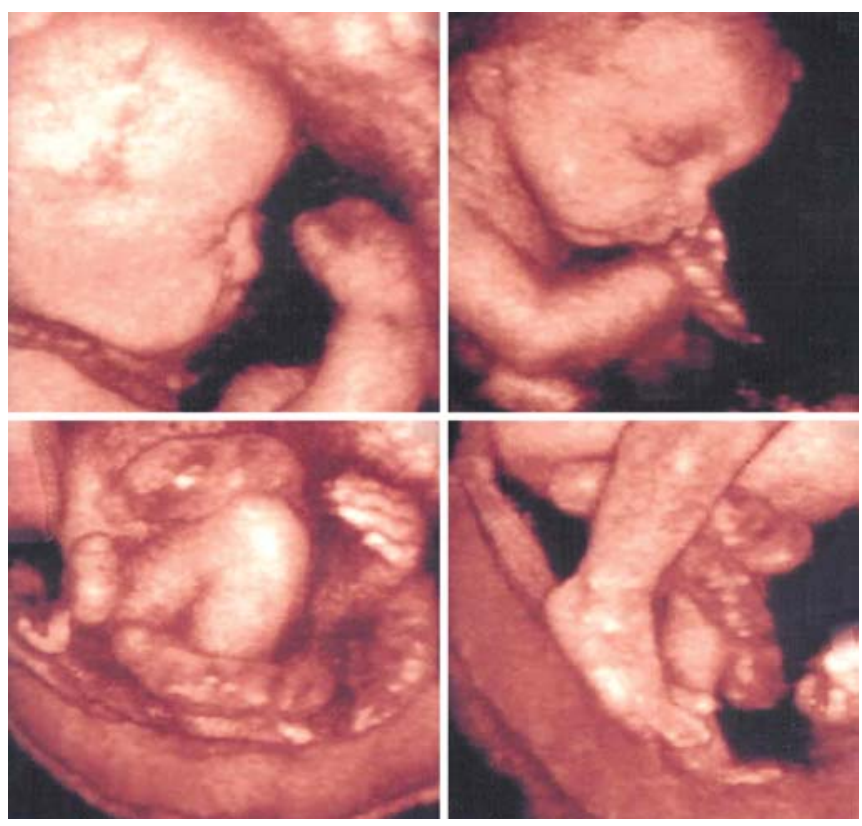

Fig. 2: Third trimester. Fetuses with loops around the neck (above left), hand (above right), foot (below left) and two loops around the leg (below right) 


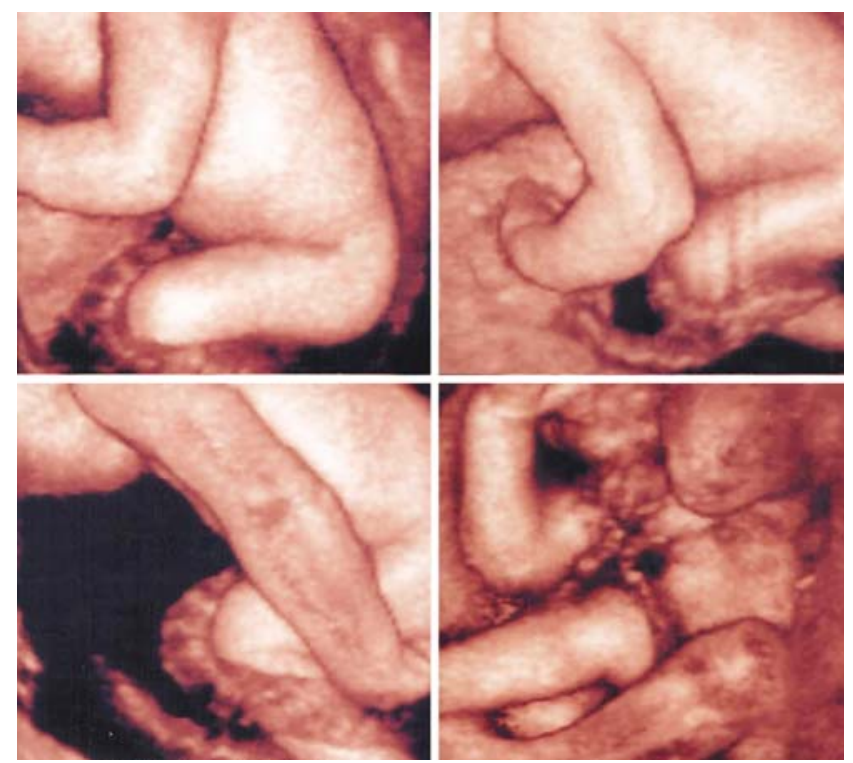

Fig. 3: Umbilical cord images showing loops around the thigh and legs. Almost $30 \%$ of the fetuses are born with nuchal entanglement, thus, it must be considered a physiological finding

arm. ${ }^{16,17}$ These events can be clearly observed with threedimensional (3D) ultrasonography ${ }^{16,18,19}$ (Fig. 3).

There is still controversy about the clinical significance of cord entanglement, but given the frequency with which it is seen, it must be considered as a physiologic event. Cord entanglement is not usually a problem during pregnancy or during labor and delivery. However, in rare case multiple, tight loops may interfere with blood flow that results in fetal distress or even fetal death. ${ }^{20,21}$ Cord accidents, blood flow impairment problems, amputations, death by strangulation, premature placental separation, etc. have been described in relation to cord entanglement. Cord entanglement has also been associated with an increase in the number of pathologic monitor tracings, fetal acidosis, meconium-stained amniotic fluid, emergency cesarean sections, admission to neonatal intensive care units (NICU) and possibly with higher rates of perinatal mortality. ${ }^{22,23}$ The presence of severe variable decelerations antepartum or intrapartum on the monitor tracing should lead obstetricians to consider a possibility of cord entanglement, but this would be a late diagnostic sign.

\section{Diagnostic Means}

\section{D Ultrasound}

Loops of cord involved in entanglement can be seen with two-dimensional (2D) ultrasonography, but it is not easy diagnose with this mode. Toward the end of pregnancy it is difficult, if not impossible, to see the entire neck of the fetus. There are many reports of nuchal cord diagnosis with $2 \mathrm{D} .{ }^{22}$ $\mathrm{N}$ evertheless, this event may be missed due to the poor sonic reflection of umbilical cord blood vessels. At times it is difficult to observe the entire trajectory of the cord. This problem may occur even with the most sophisticated machines. ${ }^{27}$

\section{Color Doppler and Doppler Energy}

These modes are exceptionally useful for detecting cord entanglement and should be the diagnostic ' gold standard' $24-26$ (Fig. 4).
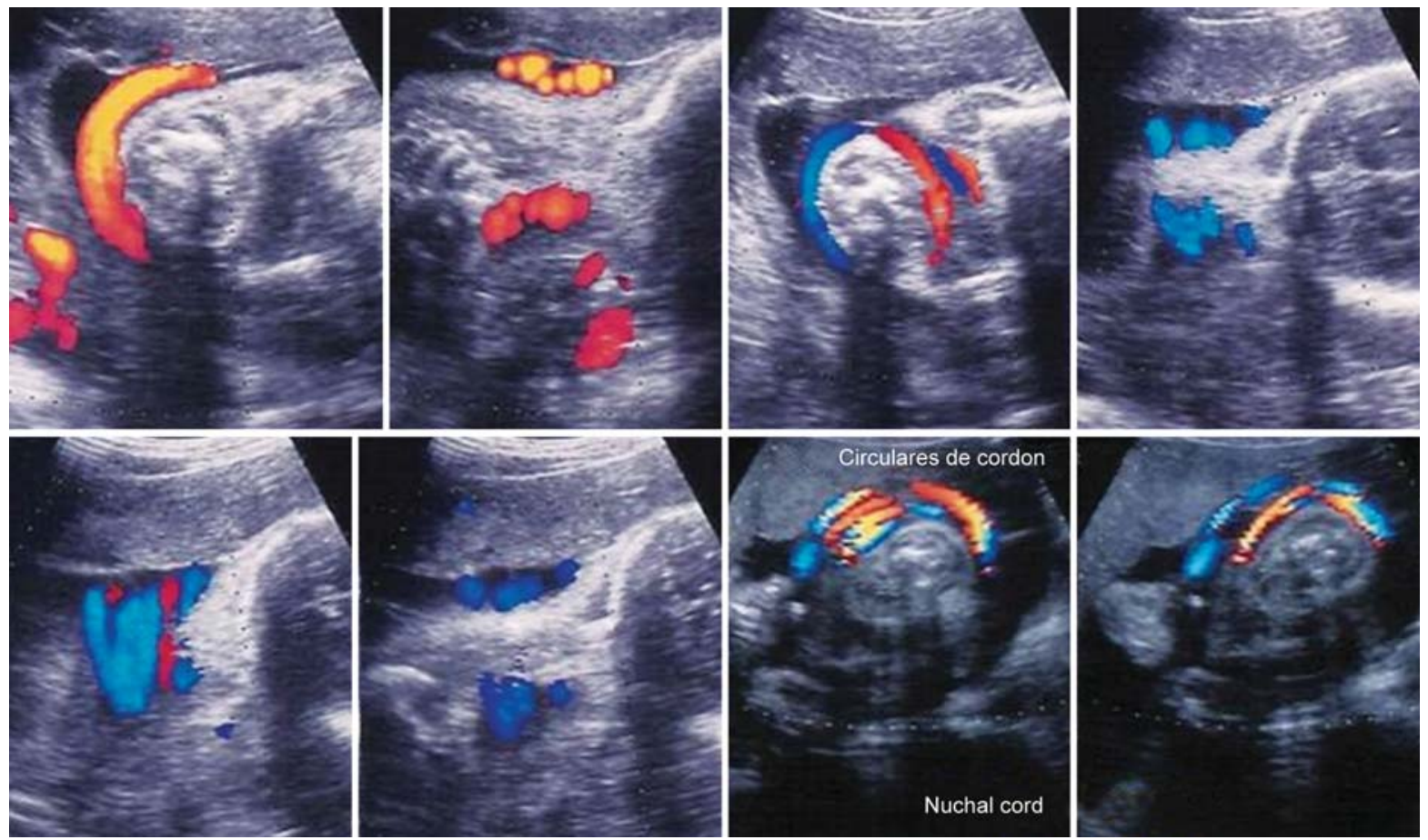

Fig. 4: Color Doppler showing a cord loop around the neck. Although this image is a typical finding with 2D, it is not always seen clearly. Sometimes it is difficult to be suspected if this technology (Doppler) is not used. The below right picture shows two loops around the neck 
Umbilical Cord Entanglement: Diagnostic and Clinical Repercussions

Examination with Doppler can at times be long and tedious due to the scant sonic reflection of blood vessels, and at times it is difficult to see the entire trajectory of the cord. ${ }^{27}$

There are many reports that confirm the diagnostic importance of these Doppler modes. ${ }^{24,26,28}$ They facilitate detection and provide a sensitivity of $79 \%{ }^{29}$ that increases to $93 \%$ and to $97 \%$ at 32 and 36 gestational weeks ${ }^{24,30,31}$ with a positive predictive value (PPV) of $89 \%$, a negative predictive value (NPV) of $96 \%$, and an efficiency of $93 \%$ during labor, ${ }^{6,29}$ which is superior to the $33 \%$ efficiency obtained with 2D. Global sensitivity would be of $95 \%$ with a specificity of $92 \%$ for a PPV of $82 \%$ and a N PV of $98 \%{ }^{32}$

\section{Tomographic Ultrasound Imaging}

With this mode, multiple serial cuts that are separated by millimeters are carried out. When combined with Doppler, diagnosis of cord entanglement can be completed since loops can be observed millimeter by millimeter for the entire cord extension (Fig. 5).

\section{Three-dimensional/F our-dimensional Ultrasound Imaging}

Three-dimensional (3D) systems in real time and multiplanar mode as well as four-dimensional (4D) have facilitated

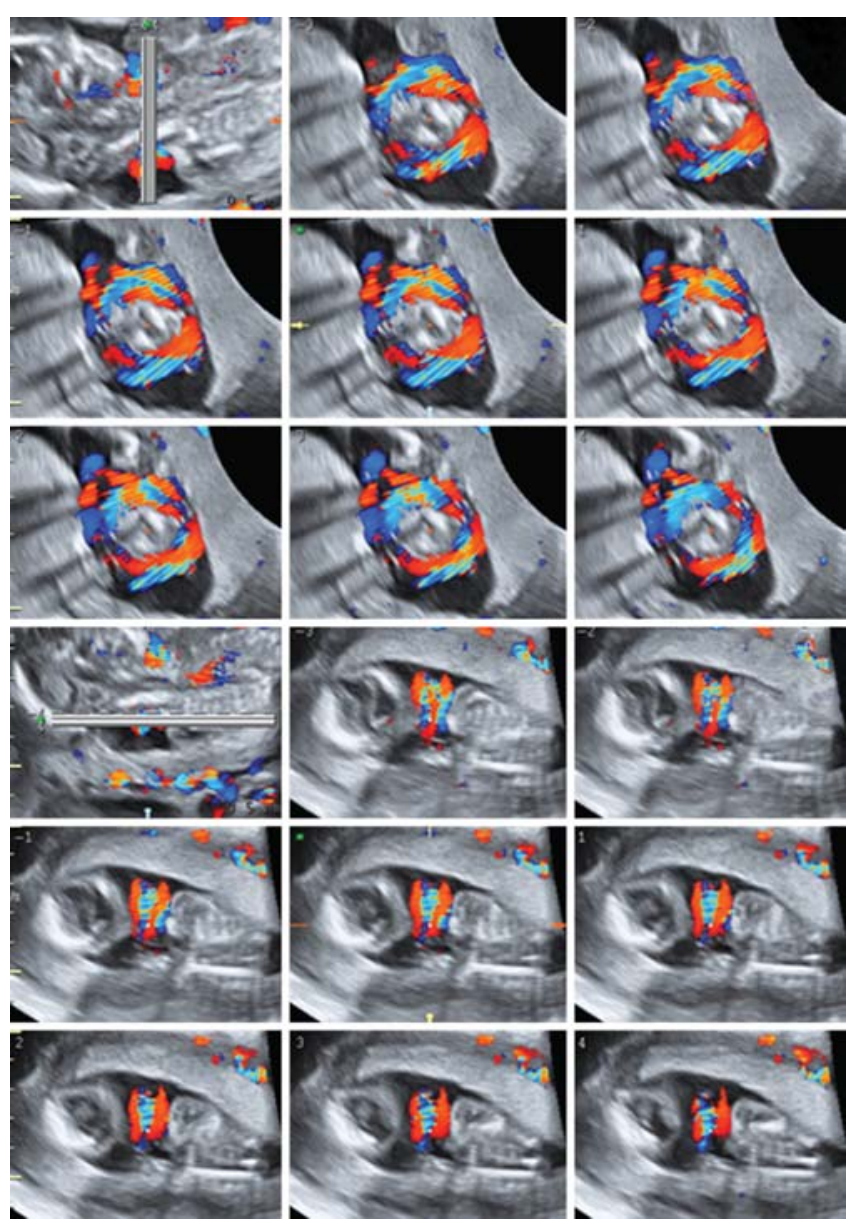

Fig. 5: Above TUI. Multiple tomographic sections of a single loop in sagittal view. Below in longitudinal view but showing a double loop
Table 1: Ultrasound technique (diagnostic differences)

\begin{tabular}{llcl}
\hline Parameter & 2D & Doppler & 3D \\
\hline Sensitivity & 68.5 & 71.4 & 82.9 \\
Specificity & 80 & 82.4 & 77.7 \\
PPV & 58.5 & 62.5 & 60.4 \\
NPV & 86.1 & 87.5 & 91.7 \\
False negative index & 31.4 & 28.6 & 17.1 \\
False positive index & 20 & 17.7 & 22.4 \\
Reliability & 76.7 & 79.2 & 79.2 \\
\hline
\end{tabular}

Sensitivity, specificity, P PV and NPV according to the diagnostic technique used (From Hanaoka $U$ et $\mathrm{al}^{30}$ )

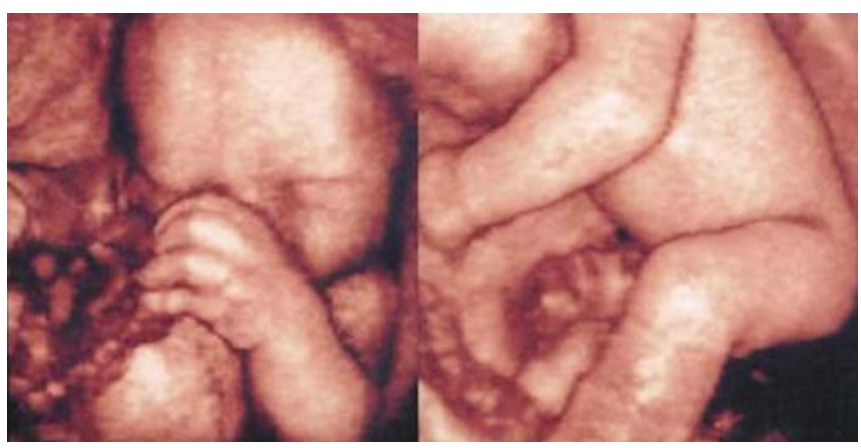

Fig. 6: Umbilical cord showing two loops around the leg (right) and then going up to the face (left)

diagnosis of cord entanglement as well as of other cord pathologies, such as knots, tumors and cysts. ${ }^{1-4,30,33} \mathrm{~A}$ comparative study 2D/D oppler/3D of pregnancies at term ${ }^{30}$ revealed the following diagnostic differences for each of these modes (Table 1).

The ability to see the loops was greater using $3 \mathrm{D}$ than $2 \mathrm{D}$ or D oppler, improving diagnostic security indexes. ${ }^{1-4,7,17,21,26}$

3D real-time allows the loops visualization from the gestational week when appeared facilitating the early diagnosis and follow-up (Fig. 6).

\section{Gestational Age}

Practically, all studies about cord entanglement have been carried out in the last weeks of gestation. However, it is advisable to try to diagnose this event at the end of the firsttrimester during 'prenatal diagnosis.' This is an ideal moment to carry out the study because the whole fetus can be observed with 3D (Fig. 7). Visualization of the cord should be a part of the morphological study, as is done with nuchal translucency and nasal bone. In this way it is possible to follow the events that take place during the remainder of the pregnancy, since, as we will show further ahead, most cord entanglements persist up to the time of delivery.

Cord assessment at the end of the first trimester represents an important diagnostic step that can help avoid complications further ahead in the gestation, since multiple loop entanglements can have repercussions during pregnancy and during labor and delivery (Fig. 7). 


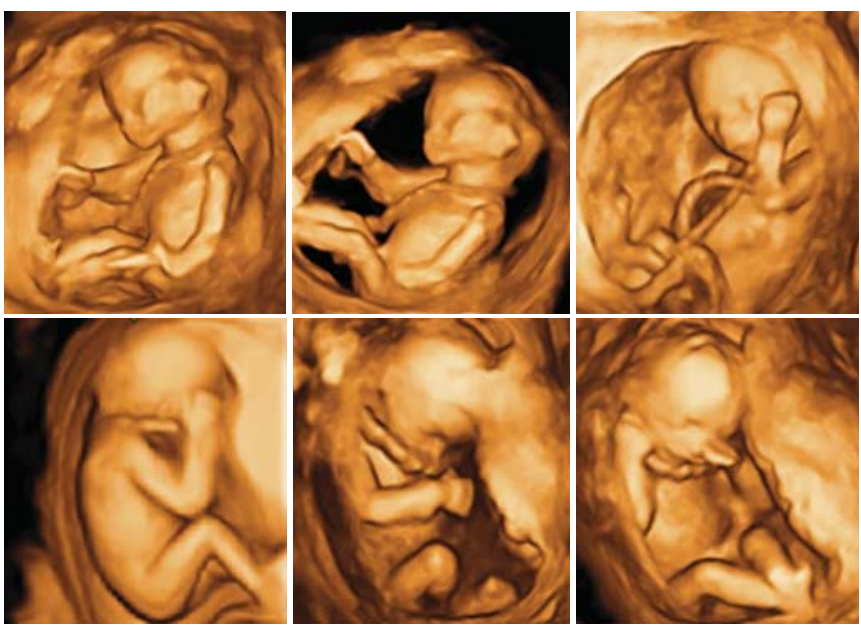

Fig. 7: Above, 3D of a nuchal cord loop in week 14th. In the middle, the same loop in frontal and sagittal 3D view. The combination of such images allows to show how the cord ascend from the umbilicus, producing a loop and goes down to the abdomen making like a 'scarf' or a 'shoulder belt'. Below, loop located between the thorax and the mandible. The cord coiling is clearly seen

Early diagnosis will also allow obstetricians to distinguish between true entanglements from less significant events, such as loops around the abdomen, knots, cysts, etc. We will show further ahead that there are entanglements that are present in the first-trimester and then disappear, while others appear in the second-trimester, or more so, in the third-trimester. It is not difficult to search for them during the anatomic survey that is carried out between the 18 and 24 weeks of gestation or in the third-trimester.

\section{Number of Loops}

The new ultrasound techniques allow the determination of the number of loops involved in cord entanglement from the first-trimester on. The risk of an adverse outcome for the fetus increases as the number of loops increase (Figs 8 and 9).

We have observed the following incidence of loops in nuchal cords:

- Overall in the first-trimester, $25.3 \%$

- One loop in $18.7 \%$ of cases

- Two loops in $6 \%$ of cases

- Three loops in $0.7 \%$ of cases

- Persistent loops at 20 weeks gestation, $16.8 \%$

- One loop in $13.4 \%$

- Two loops in 3.4\%

- Loops present at 32 weeks gestation, $18.2 \%$

- One loop in $15.2 \%$

- Two loops in $2.7 \%$

- During delivery, $29.3 \%$ had nuchal cords

- $22.7 \%$ with one loop

- $5.3 \%$ with two loops

- $1.3 \%$ with three loops
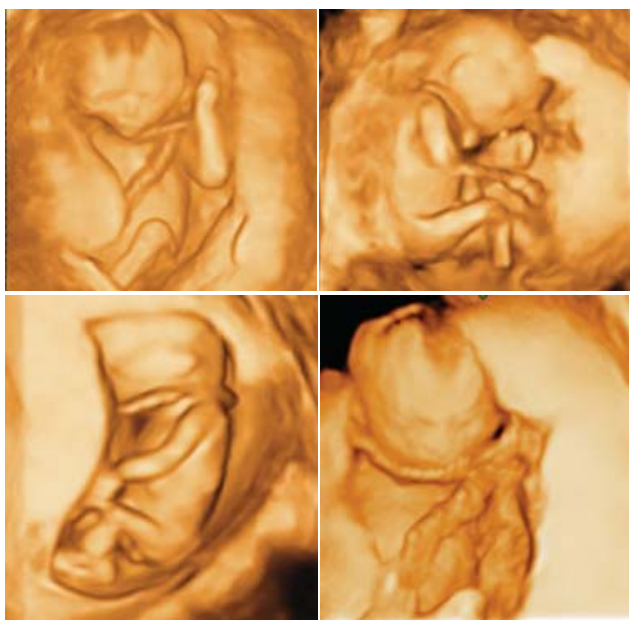

Fig. 8: Four 3D images of a cord ascending to surround the neck showed in different views
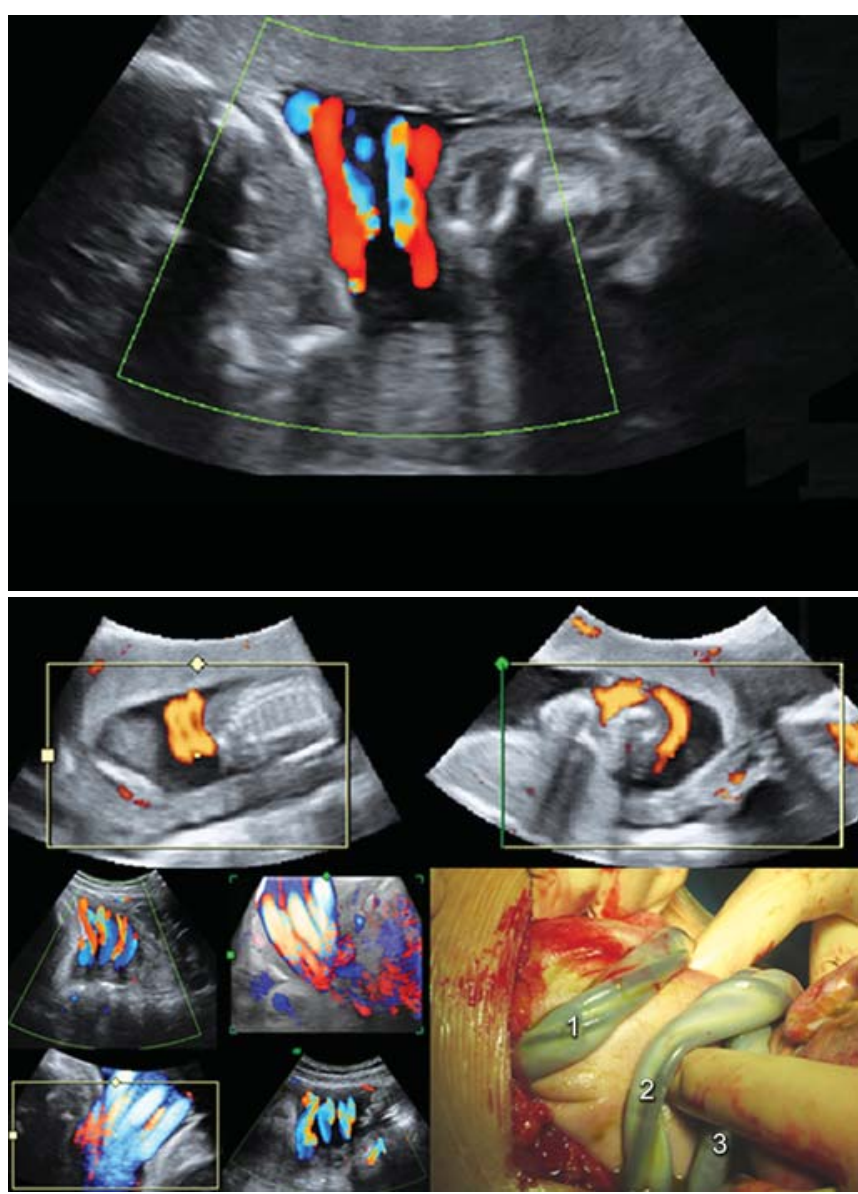

Fig. 9: Multiple cord loops

Most nuchal cords persisted throughout gestation, although the number of nuchal cords increase at the end of gestation.

\section{Repercussions and Clinical Interest}

Clinical interest about cord entanglement centers about the possible reduction in venous circulation that would result with tight loop compression. The result would be immediate 
fetal hypoxia and central hypovolemia. Data from serial studies $^{22}$ have shown that cord compression for more than 10 minutes results in a reduction of cerebral vascular flow resistance al ong with a fall in partial $\mathrm{pO}_{2}$ pressure.

These alterations only take place if there is nuchal cord compression. This is why these manifestations are more common during the active phase of the second stage of labor and why there are only a few newborn babies with nuchal cords which are severely affected at the time of birth. Since, identification of babies at risk can lead to appropriate and timely intervention, there is interest in early diagnosis of umbilical cord entanglement. ${ }^{34-36}$

Classical reviews have described a higher frequency of meconium-stained amniotic fluid (two to six times, between 10 and $20 \%$ of cases), a higher rate of inductions, slow labor progress, shoulder dystocia, low blood pH (20 to 30\%), higher cesarean section rates, a greater need for immediate neonatal resuscitation and a higher rate of NICU admissions. ${ }^{37-39}$ It seems that cord entanglements that restrict fetal movement are the ones that are at increased risk of adverse perinatal outcome. ${ }^{2,37}$

$M$ anagement of nuchal cord cases with multiple loops is more debatable. In cases of multiple loops compared with a single $100 p^{40}$ a greater tendency to cardiac frequency al terations during labor was observed, more instrumentation was required, there were more low A pgar cases and more cases of blood pH below 7.10; but curiously, the cesarean section rates were not significantly different nor were the A pgar scores worse. ${ }^{41}$ The authors conclude that prospective decisions should not be made based on ultrasound multipleloop nuchal cord diagnosis., ${ }^{40,42}$

It is of interest that there are reports of nuchal cord with transitorily increased nuchal translucency that resolves after the 14th week of gestation, and with normal karyotypes and ultrasound findings at 18 to 20 weeks gestation. These findings are important for the prevention of decisions on false positive nuchal translucency results. ${ }^{8}$

In our study of 150 cases observed from the first trimester until the end of gestation there were only to fetal deaths ( $1.3 \%$ of the sample), both of which had tight double loops, with fetal demise at 14 and 20 weeks gestation ( 2 of 9 cases, $22 \%$ ). Evidence suggests that risk increases with the number of loops involved (Fig. 10). B ut these data, as we will show further ahead, do not justify cesarean section based on this finding.

In our series, $82.6 \%$ ended pregnancy with a vaginal delivery. Spontaneous vaginal delivery occurred in $63.3 \%$ of gestations and instrument-assisted vaginal delivery (forceps or vacuum extraction) in $19.3 \%$. Of the $16 \%$ gestations that had a cesarean delivery, only $1.3 \%$ were sectioned because of a suspicion of loss of fetal well-being.

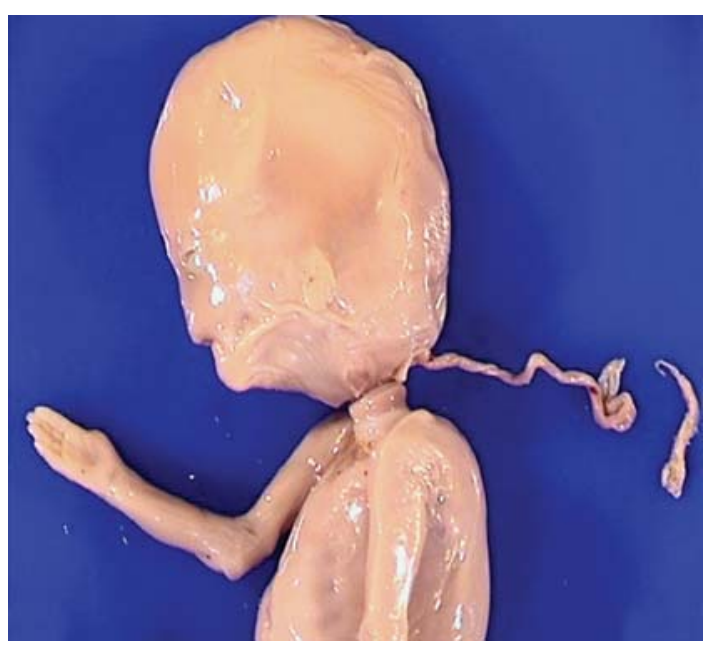

Fig. 10: Fetal obitus in week 14 due to two tight cord loops

The fetal monitor graphs were normal in $77.7 \%$ of cases. There were variable decelerations in $13.5 \%$, early decelerations in $8.1 \%$ and only $0.7 \%$ had late decelerations. There were 8 cases with cord $\mathrm{pH} \leq 7.20$.

When we compared nuchal cords diagnosed at 12 to 14 weeks with those seen on week 20, week 32, and at delivery, we observed that there was a correlation, but there was no relation with A pgar scores or with blood pH. There was an inverse correlation between the number of loops seen at the 20th week of gestation and subsequently with the lowest $\mathrm{pH}$ values.

\section{COMMENTS}

U mbilical cord entanglement is a frequent finding in deliveries. Its prevalence at birth varies between 15 and $25 \%$ and is considered a physiologic event. It has been reported that the presence of two or more loops around the fetal neck occurs in between 2.5 and $8.3 \%$ of pregnancies. . $^{910,41,42}$ Cord entanglement can be diagnosed with 2D ultrasonography and Doppler, although more recently and especially in the early stages of pregnancy $3 \mathrm{D}$ is recommended.

The presence of nuchal cord or other entanglement is not usually associated with alterations in fetal oxygenation. In very few cases is fetal health compromised and vaginal birth is contraindicated. Nevertheless, at times during labor a loop can become tight and affect blood flow and fetal oxygenation as the presenting part descends through the birth canal. This condition can be detected with proper monitoring of labor progress and with appropriate determination of blood $\mathrm{pH} .{ }^{6,42}$

Although there seems to be a linear increase in the number of nuchal cords with gestational age, it is also true that these may appear and disappear with time. ${ }^{11} \mathrm{~A}$ greater incidence of nuchal cord has been reported in white women and in male fetuses. ${ }^{11,32,40}$ 
There are multiple reports in the world literature that address the implications of cord entanglement during labor, delivery, and in newborn babies, but only a few, like this one, follow this event throughout the entire gestation. We have used for this study 3D/4D ultrasound assisted with Doppler and 3D angiography, which are aids that afford great diagnostic precision.

In nuchal cord cases we have not observed changes in flow velocimetry of the middle cerebral artery nor in the umbilical cord, since if there are interruptions of flow, they are only intermittent. If cord compression is not prolonged, flow does not cease in any significant way and fetal reserve can maintain adequate oxygenation. ${ }^{32} \mathrm{~N}$ evertheless, the numer of coils was reduced in nuchal cords and there was an inverse relationship between the number of coils and susceptibility to cord occlusion. ${ }^{2} \mathrm{M}$ aybe nuchal cords predispose to cord compression that can be associated with a higher rate of bradycardias, variable decelerations, umbilical cord acidemia, an increase in free oxygen radicals, and although rare, fetal demise. ${ }^{12,32}$

When there is cord occlusion, the most frequent change in fetal heart rate observed is variable deceleration. ${ }^{11} \mathrm{~F}$ or this reason a significant increase in alterations of intrapartum fetal heart rate patterns has been described. ${ }^{11,40} \mathrm{~A}$ larger number of loops has also been associated with the most severe cases of growth restriction. ${ }^{13,40}$

When comparing newborn babies who had no nuchal cord with those born with one loop, two loops and multiple loops, we found no differences in birth weight, in heart rate alterations, in incidence of operative vaginal delivery or in A pgar scores. There was only a significant difference in the rates of cesarean birth, which resulted from evidences of nonreassuring fetal heart rate patterns or of cord compression during labor that were associated with low A pgar scores, but there was no correlation with the worst perinatal outcomes. ${ }^{14,15,39}$ Retrospective studies also conclude that an association of nuchal cord with significant neonatal morbidity and mortality rarely occurs.

Studies about the incidence of nuchal cord in term and post-term pregnancies have established incidences of 33.7\% at term (5.8\% with multiple loops) and of $35.1 \%$ post-term (5.5\% with multiple loops) with an increase rate of meconium staining and more severe cases of low pH ocurring in post-term babies with multiple loops. There were no differences with other variables. The authors concluded that the presence of nuchal cord should not influence the clinical management of labor and delivery and that primary neonatal adaptation was not affected. ${ }^{42-45}$

W e conclude that since nuchal cords in the first-trimester do not imply in themselves poor perinatal outcomes, they should only be observed during gestation without a need for increased surveillance. ${ }^{46,47}$ It is important to realize that if present in the first-trimester, there is an increased probability that they will persist throughout pregnancy, and that if they persist, especially if multiple loops are involved, they are correlated with deliveries that are managed more aggressively and with a higher rate of complications.

\section{CONCLUSION}

- The incidence of nuchal cord diagnosed in the first trimester with 3D/4D and Doppler ultrasonography is of about $25.3 \%$ (one loop in $18.7 \%$, two loops in $6 \%$, and three loops in $0.7 \%$ of cases).

- These percentages remain with small variations throughout pregnancy (they can increase or decrease), with $16.8 \%$ in week 20 and $18.2 \%$ in week 32 . A t birth, the number increases to $29.3 \%$.

- Analysis of the type of delivery indicates that most babies $(82.6 \%)$ are delivered vaginally. The cesarean section rate was $16 \%$, but only $1.3 \%$ were sectioned because of a suspicion of fetal distress.

- The incidence of fetal demise was very low (1.3\%), and fetal death was always early in gestation and associated with multiple loops.

- There is a correlation between the presence of nuchal cord in the first-trimester and its presence later on in pregnancy. However, there is no correlation with adverse pregnancy outcome. The presence of nuchal cord at weeks 20 and 32 of gestation only correlated with the worst cases of fetal acidosis with an increasing number of loops in the nuchal cord.

- The new ultrasound modes [Doppler, 3D/4D, tomographic ultrasound imaging (TUI)], are diagnostic instruments of great precision.

\section{REFERENCES}

1. B onilla-M usoles F, M achado LE, Osborne N G, Raga F, B onilla F Jr, Puig MJ, M achado F. M orphological assessment of the umbilical cord with three-dimensional ultrasonography. Ultrasound Rev Obstet Gynecol 2002;2:17-42.

2. Bonilla-M usoles $F, M$ achado $L E$, Osborne NG, Raga $F$. $M$ orphological evaluation of the umbilical cord. In: BonillaM usoles F, M achado LE (Eds): 3D in O bstetrics. Panamericana. M adrid 2004;361-90.

3. B onilla-M usoles F, Raga F, B onilla F J r, Blanes J, Osborne N, B ailão LA , et al. Sonoembriología tridimensional transvaginal. In: Bonilla-M usoles $F(E d)$. Ecografía V aginal Doppler y Tridimensión. Panamericana Ed. M adrid 2000:27-96.

4. Osborne NG, B onilla-M usoles F, Raga F, Blanes J, B onilla $F$ J r. U mbilical cord cysts: Colour Doppler and three-dimensional evaluation. Ultrasound Quarterly 2000;16:133-39.

5. Jouppila P, K irkinen P. Ultrasonic diagnosis of nuchal encirclement by the umbilical cord: A case and methodological report. J Clin UItrasound 1982;10:59-62. 
Umbilical Cord Entanglement: Diagnostic and Clinical Repercussions

6. Barron EM , M artínez P, M ontalvo J. V aloración ecográfica del cordón umbilical. In: Bajo A renas (Ed). Ultrasonografía Obstétrica. M adrid: M arbán 2005;335-51.

7. Sherer DM, M anning FA. Prenatal ultrasonographic diagnosis of nuchal $\operatorname{cord}(s)$ : Disregard, inform, monitor or intervene? Ultrasound Obstet Gynecol 1999;14:1-8.

8. Maymon $R$, Herman A, Dreazen E, Tovbin $Y, B$ ukovsky I, Weinraub Z. Case report: Can nuchal cord cause transient increased nuchal translucency thickness? Human Reproduction 1999:14:556-59.

9. Dhar KK, Ray SN, Dhall GI. Significance of nuchal cord. J Indian Med Assoc 1995;93:451-57.

10. Hankins GVD, Snyder RR, H auth J C, Gilstrap LC, Hammond T. Nuchal cords and neonatal outcome. Obstet Gynecol 1987;70:687-91.

11. Hasegawa J, M atsuoka R, Ichizuka K, Sekizawa A, Okai T. Ultrasound diagnosis and management of umbilical cord abnormalities. Taiwan J Obstet Gynecol 2009;48:23-27.

12. Collins JH. Two cases of multiple umbilical cord abnormalities resulting in stillbirth: Prenatal observation with ul trasonography and fetal heart rates. A m J Obstet Gynecol 1993;168:125-28.

13. Sornes T. U mbilical cord encirclements and fetal growth restriction. Obstet Gynecol 1995;86:725-29.

14. M astrobattista J M, Hollier LM, Y eomans ER, Ramin SM . Effects of nuchal cord on birthweight and immediate neonatal outcomes. A m J Perinatol 2005;22:83-85.

15. Palacios M . V alidación del ultrasonido como prueba diagnóstica para circular de cordón durante el trabajo de parto. Estudio preliminar. Ginecol Obstet 2002;48:1-4.

16. B onilla-M usoles $F, M$ achado $L$, Osborne $N$. The umbilical cord. In: Bonilla-M usoles F, M achado L, Osborne N (Eds). Three-Dimensional Ultrasound for the new Milenium: Text and A tlas. Fotocomposición Crisol SL (Ed). A loka M adrid 2000;163-72.

17. Dursun P, Salman M C, Ozyuncu O, A ksu T. Nuchal cord type $B$ associated with an excessively long umbilical cord as a cause of stillbirth: A case report. Clin Exp Obstet Gynecol 2004;31: 158-59.

18. Malpas $P$, Symonds $E M$. Observations on the structure of the human umbilical cord. Surg O bstet Gynecol 1996;123:746-50.

19. Strong TH. Factors that provide optimal umbilical protection during gestation. Contemporary OB/GY N 1997;42:82-105.

20. Shestha NS, Singh N. Nuchal cord and perinatal outcome. Kathmandu U niv M ed J 2007;5:360-63.

21. Sheiner E, A bramowicz JS, Levy A, Silberstein T, M azor M, Hershkovitz R. Nuchal cord is not associated with adverse perinatal outcome. Arch Gynecol O bstet 2006;274:81-83.

22. Sepúlveda W, Shennan A H, B ower S, Nicolaides P, Fisk NM . True knot of the umbilical cord: A difficult prenatal ultrasonographic diagnosis. UItrasound Obstet Gynecol 1995;5:106-08.

23. Hertzberg BS, B owie JD, Bradford W D, Bolick D. False knot of the umbilical cord: Sonographic appearance and differential diagnosis. J Clin Ultrasound 1988;16:559-602.

24. J auniaux E, M awissa C, Peellaerts C, Rodesch F. Nuchal cord in normal third-trimester pregnancy: A color Doppler imaging study. U Itrasound. O bstet Gynecol 1992;2:417-19.

25. Pilu G, Falco P, Guazziarini M, Sandri F, Bovicelli I. Sonographic demonstration of nuchal cord and abdominal umbilical artery waveform heralding fetal distress. Ultrasound Obstet Gynecol 1998;12:125-27.

26. Qin Y, W ang C, Lau TK, Rogers M S. Color ultrasonography: A useful technique in the identification of nuchal cord during labor. UItrasound Obstet Gynecol 2000;15:413-17.

27. Sepúlveda $\mathbf{W}$. Time for a more detailed examination of the umbilical cord? UItrasound O bstet Gynecol 1999;13:157-60.

28. Funk A, Heyl W, Rother R, W inkler M, Rath W. Subpartal diagnosis of umbilical cord encirclement using color-coded Doppler ul trasonography and correlation with cardiotocographic changes during labor. G eburtsh Frauenheilk 1995;55:623-27.

29. Jauniaux E, Ramsay R, Paellaerts C, Rodesch F. Prenatal features of pregnancies complicated by nuchal cord. A m J Perinatol 1995; 12:255-58.

30. Hanaoka U, Y anagihara T, Tanaka H, Hata T. Comparison of three-dimensional, two-dimensional and color Doppler ultrasound in predicting the presence of a nuchal cord at birth. Ultrasound Obstet Gynecol 2002;19:471-74.

31. Xu H, Dai WP, Wang CJ, Tian LX, Tang HM, Sun FQ. Prediction of fetal hypoxia by measuring middle cerebral and umbilical artery resistance index in fetuses with umbilical cord around the neck in late pregnancy. Nan Fang Y i Ke X ue X ue Bao 2008;28:2207-09.

32. A ksoy U. Prenatal color Doppler sonographic evaluation of nuchal encirclement by the umbilical cord. J Clin Ultrasound 2003;31:473-77.

33. Hata T, A oki S, Hata K, M iyazaki K. Three-dimensional ultrasonographic assessment of the umbilical cord during the 2nd and 3rd trimesters of pregnancy. Gynecol Oncol Invest 1998;45:159-64.

34. Hübner G. Asfixia perinatal. Edición Servicio Neonatología Hospital Clínico Universitario de Chile 2001;9:64-69.

35. V ispo S, M eane J, K aratanasóputoz M, Casal J. Sufrimiento fetal agudo: Revisión. Revista de Postgrado de la V I Cátedra de Medicina 2002;112:21-26.

36. Pérez González J $M$. A noxia del recién nacido. In: Cruz $M$, Crespo M , B rines J , J iménez $R$, M olina J A. M anual de Pediatría. Madrid: Ed. Ergon 2010:66-69.

37. Sherer DM , Heam B, Woods JR. Possible intermittent umbilical cord occlusion. J Ultrasound M ed 1990;9:181-91.

38. Petrikovsky BM, Kaplan GP. Fetal grasping of the umbilical cord causing variable fetal heart rate decelerations. J Clin Ultrasound 1993;21:642-44.

39. Ogue $0, A \mid$-Tarkait $A$, V allerand $D$. Obstetrical factors related to nuchal cord. A cta Obstet Gynecol Scand 2006;85:814-18.

40. Larson JD, Rayburn WF, Crosby S. Multiple nuchal cord entanglements and intrapartum complications. A m J Obstet Gynecol 1995;173:1228-31.

41. Larson JD, R ayburn WF, H arlan V L. N uchal cord entanglements and gestational age. A m J Perinatol 1997;14:555-59.

42. W ang $Y$, Le Ray C, A udibert F, Wagner M S. M anagement of nuchal cord with multiple loops. Obstet Gynecol 2008;112: 460-61.

43. Schäffer $L$, B urkhard $T$, Zimmermann R. N uchal cords in term and postterm deliveries, do we need to know? Obstet Gynecol 2005;106:23-28.

44. Ghosh GS, Gudmundsson S. Nuchal cord in post-term pregnancy-relationship to suspected intrapartum fetal distress indicating operative intervention. J Perinatal Med 2008;36: 142-44. 
45. Sadan O, Fleischfard Z, Everon S, Golan A, L urie S. Cord around the neck: Should it be severed at delivery? A randomized controlled study. A m J Perinatol 2007;24:61-64.

46. Rogers M S, I P Y W, Q in Y, Rogers SM, Sahota D. Relationship between umbilical cord morphology and nuchal cord entanglement. A cta O bstet Gynecol Scand 2003;82:32-37.

47. M arkov D, M ilanova K, Imitrov A, M arinov B, Nikolov A, Ivanov S. N uchal cord between 37 and 42 completed weeks of gestation-diagnosis and prognostic value. Akush Ginekol 2007:46:3-10.

48. Collins J H. Nuchal cord type A and type B. A m J O bstet Gynecol 1997;177:94-99.

\section{ABOUT THE AUTHORS}

\section{Ana Martínez-Aspas}

Department of Obstetrics and Gynecology, U niversity of Valencia School of M edicine, A venida B lasco I báñez 17, 46011 V alencia, Spain

\section{Francisco Raga}

Department of Obstetrics and Gynecology, U niversity of Valencia School of M edicine, A venida Blasco I báñez 17, 46011 V alencia, Spain

\section{Luiz E Machado}

Professor, Department of Obstetrics and Gynecology, U niversity of Valencia School of Medicine, A venida Blasco Ibáñez 17, 46011 $\checkmark$ alencia, Spain

\section{Francisco Bonilla J r}

Department of Obstetrics and Gynecology, University of Valencia School of M edicine, A venida Blasco I báñez 17, 46011 V alencia, Spain

\section{J uan Carlos Castillo}

Department of Obstetrics and Gynecology, U niversity of Valencia School of M edicine, A venida Blasco I báñez 17, 46011 V alencia, Spain

\section{Newton G Osborne}

Professor and Chairman, Department of Obstetrics and Gynecology Hospital M aterno I nfantil J osé D omingo De O baldía, David, Chiriquí República de Panamá

\section{Fernando Bonilla-Musoles (Corresponding Author)}

Professor and Chairman, Department of Obstetrics and Gynecology University of $V$ alencia School of M edicine, A venida B lasco I báñez 17 46011 V alencia, Spain, e-mail: profesorbonillamusoles@ hotmail.com 